\title{
POWER SERIES WITH GAPS ${ }^{1}$
}

\section{T. S. MOTZKIN}

If every $q$ th term in a power series $f(z)=a_{0}+a_{1} z+\cdots$ with finite radius of convergence is missing then $f(z)$ has at least two singularities on its circle of convergence (Mandelbrojt [1]). I proved more generally [2, Theorem 1]:

If $a_{m}=0$ for all $m \equiv \tau_{1}, \cdots, \tau_{k}(\bmod q), k \leqq 3$, where $\tau_{1}, \cdots, \tau_{k}$ for every divisor $q^{\prime}$ of $q$ belong to $\max \left(k, q^{\prime}\right)$ different residue classes, then $f(z)$ has at least $k+1$ singularities on its circle of convergence.

I wish to show here that this statement is not true for $k=4$ and $k \geqq 6$. The case $k=5$ remains open. It would be of interest to determine the minimum number $\nu$ of singularities for given $k$, as well as for given $k$ and $q$. For prime $q$ it is known [3] that $\nu \geqq k+1$.

The pertinent counterexample is

$$
f(z)=\frac{1-z^{\alpha}}{1-z^{\alpha \beta}}=1-z^{\alpha}+z^{\alpha \beta}-z^{\alpha+\alpha \beta}+\cdots,
$$

with $q=\alpha \beta$ and $\alpha \beta-\alpha$ singularities on the unit circle. Let $\tau_{1}, \cdots, \tau_{k}$ be the $q-\gamma$ numbers $0, \cdots, q-1$ after deletion of $0, \cdots, \gamma-2$ and $\alpha$, where $2 \leqq \gamma \leqq \alpha$. If $\beta \geqq 3$ then, for every proper divisor $q^{\prime}$ of $q$, all residue classes are represented by $q-q^{\prime}, \cdots, q-1$. However, $\alpha \beta-\alpha \leqq k$.

For given $k$, the choice of $\alpha$ (not exceeding $k / 2$ and not dividing $k+1)$ determines $\beta$ and $\gamma$ uniquely. Set $\alpha=[k / 2], \beta=3, \gamma=k / 2$ or $(k-3) / 2$; then $\gamma \geqq 2$ excludes only $k=1,2,3,5$.

\section{REFERENCES}

1. S. Mandelbrojt, Sur les séries de Taylor qui présentent des lacunes, Ann. Sci. Ecole Norm. Sup. (3) vol. 40 (1923) pp. 413-462.

2. T. S. Motzkin, Bemerkung über Singularitäten gewisser mit Lücken behafteter Potenzreihen, Math. Ann. vol. 109 (1933) pp. 95-100; in Theorem 1, Condition 1 is to be taken in its stronger meaning: "in" classes does not imply exhaustion of those classes.

3. A. Ostrowski, Mathematische Miszellen. VII: Über Singularitäten gewisser mit Lücken behafteten Potenzreihen, Jber. Deutsch. Math. Verein. vol. 35 (1926) pp. 269280.

\section{University of California, Los ANgeles}

Presented to the Society, April 23, 1960; received by the editors August 10, 1959.

${ }^{1}$ Sponsored, in part, by the Office of Naval Research. Reproduction in whole or in part is permitted for any purpose of the United States Government. 